\title{
Comfort Level of Emergency Medical Service Providers in Responding to Weapons of Mass Destruction Events: Impact of Training and Equipment
}

\author{
Michael J. Reilly, MPH, NREMT-P; ${ }^{1}$ David Markenson MD, EMT-P; ${ }^{2}$ \\ Charles DiMaggio, PhD, PA-C ${ }^{3}$
}

1. Assistant Director, Center for Disaster Medicine, Assistant Professor of Public Health Practice, New York Medical College, School of Public Health, New York, New York USA

2. Principal Investigator, CDC TIIDE Grant National Association of EMTs, Director, Center for Disaster Medicine, Associate Professor of Public Health and Associate Professor of Pediatrics, New York Medical College and Chief, Pediatric Emergency Medicine, Maria Fareri Children's Hospital, New York, New York USA

3. Assistant Professor of Clinical Epidemiology, Columbia University, Mailman School of Public Health, New York, New York USA

\author{
Correspondence: \\ Michael J. Reilly, MPH, NREMT-P \\ New York Medical College \\ SPH Bldg. 3rd Floor \\ Valhalla, New York 10595 USA \\ E-mail:michacl_reilly@nymc.edu
}

This manuscript and the data collection activities were partially supported via funding from the Centers for Disease Control and Prevention, National Center for Injury Prevention grant numbers U38/CCU422276-01 and numbers U38/CCU424164-01-1.

Keywords: bioterrorism; emergency medical services; equipment; training; weapons of mass destruction

\footnotetext{
Abbreviations:

$\mathrm{CDC}=$ (US) Centers for Disease Control and Prevention

$\mathrm{CME}=$ continuing medical education

DOJ $=$ (US) Department of Justice

EMS $=$ emergency medical services

$\mathrm{EMT}=$ emergency medical technician

FEMA = (US) Federal Emergency

Management Agency

HRSA = Human Resources and Service

Administration
}

\begin{abstract}
Background: Numerous studies have suggested that emergency medical services (EMS) providers are ill-prepared in the areas of training and equipment for response to events due to weapons of mass destruction (WMD) and other public health emergencies (epidemics, etc.).

Methods: A nationally representative sample of basic and paramedic EMS providers in the United States was surveyed to assess whether they had received training in WMD and/or public health emergencies as part of their initial provider training and as continuing medical education within the past 24 months. Providers also were surveyed as to whether their primary EMS agency had the necessary specialty equipment to respond to these specific events. Results: More than half of EMS providers had some training in WMD response. Hands-on training was associated with EMS provider comfort in responding to chemical, biological, and/or radiological events and public health emergencies (odds ratio (OR) $=3.2,95 \%$ confidence interval (CI) 3.1 , 3.3). Only $18.1 \%$ of providers surveyed indicated that their agencies had the necessary equipment to respond to a WMD event. Emergency medical service providers who only received WMD training reported higher comfort levels than those who had equipment, but no training.

Conclusions: Lack of training and education as well as the lack of necessary equipment to respond to WMD events is associated with decreased comfort among emergency medical services providers in responding to chemical, biological, and/or radiological incidents. Better training and access to appropriate equipment may increase provider comfort in responding to these types of incidents.
\end{abstract}

Reilly MJ, Markenson D, DiMaggio C: Comfort level of emergency medical services providers in responding to weapons of mass destruction events: Impact of training and equipment. Prehospital Disast Med 2007;22(4):297-303.

\section{Introduction}

The emergency medical services (EMS) system repeatedly is identified in the literature as one of the strongest components of trauma systems. ${ }^{1-7}$ In spite of this apparent strength, reports have shown major deficiencies in the preparedness of EMS agencies and systems to respond effectively to events involving weapons of mass destruction (WMD) and other public health emergencies. 3,8-14

In their 2002 survey of trauma and EMS systems throughout the United States, the Health Resources Service Administration (HRSA) reported that there was a lack of adequate training programs at the state level. ${ }^{3,13}$ The results of the HRSA survey helped to illustrate this lack of training and education among EMS personnel, as only six (12\%) states required prehospital providers to have education on disaster-related topics, only one (2\%) state required biological agent training, and three (6\%) required education on chemical agents. 3,13

$\mathrm{PPE}=$ personal protective equipment $\mathrm{WMD}=$ weapons of mass destruction
Received: 23 August 2006

Accepted: 23 October 2006

Revised: 28 November 2006

Web publication: 24 August 2007 


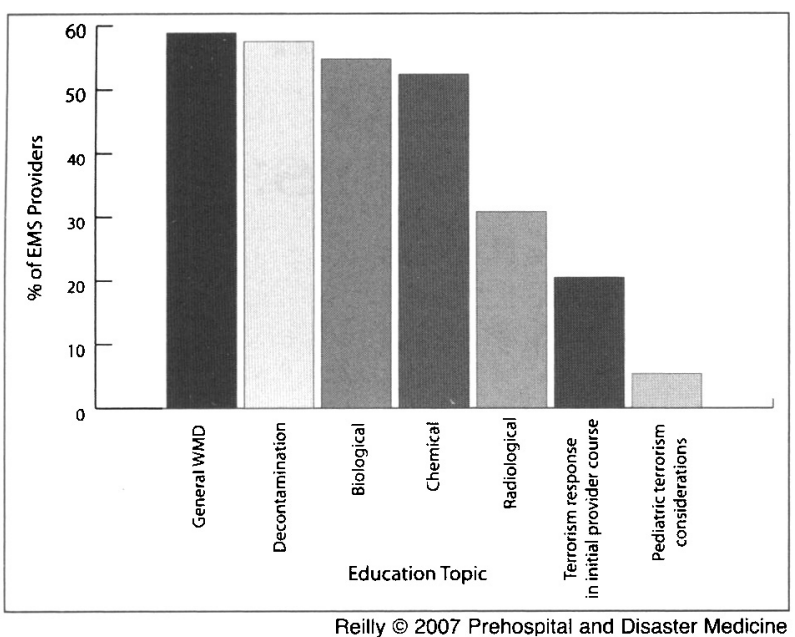

F igure 1-Yercent of emergency medical services providers who have attended terrorism-related educational programs

Additionally, results of the HRSA evaluation indicated that the availability of personal protective equipment (PPE) for all healthcare workers was lacking, as only one state (Ohio) had enough PPE resources immediately available for its EMS personnel, and only one state (New Jersey) had enough PPE resources immediately available for its hospital personnel should a chemical or biological agent release occur. ${ }^{3,13}$

The role of the EMS providers is evolving with the threat of WMD, bioterrorism, and emerging infectious diseases. Emergency medical services providers are expected to render care to patients who may be contaminated or infectious, and traditionally have not received appropriate education and training at the awareness or operations level to handle these complex situations. ${ }^{3,8-13}$ Furthermore, funding opportunities have been focused at equipment and training for law enforcement through (US) Department of Justice (DOJ) grant assistance, the fire service through the (US) Federal Emergency Management Agency (FEMA) grants, and hospitals through HRSA and the (US) Centers for Disease Control and Prevention (CDC) funding. ${ }^{11}$ With the exception of the metropolitan medical response system (MMRS) and some fire-based EMS agencies, prehospital medical first responders have been neglected by the (US) Department of Health and Human Services (DHHS), DOJ, and FEMA funding programs that have left EMS providers underequipped and under-prepared to respond to WMD events and other public health emergencies. ${ }^{3,9,11,13}$

\section{Methods}

In 2002, a nationally representative sample of 1,919 of the basic and paramedic EMS providers in the US was surveyed. Eight hundred twenty-three (42.9\%) completed questionnaires were returned. The study employed a sampling methodology that was developed and validated by the National Registry of Emergency Medical Technicians (NREMT).

The current study was an extension of an earlier prospective survey of a random population of prehospital providers certified at the Emergency Medical Technician (EMT)Basic or EMT-Paramedic level. This sample had been creat- ed to be representative of the national population and for use in a longitudinal study and in periodic surveys related to specific areas of interest regarding prehospital providers and prehospital care. The details of this sample and its use for longitudinal and snapshot analyses have been described previously. ${ }^{15-17}$ This study was approved by the Columbia University Medical Center Institutional Review Board.

Sampling was stratified by both EMT status (i.e., EMT-Basic versus EMT-Paramedic) and the duration of continuous registration at each level $(<1$ year $[$ new] or $>1$ year [old]). The sample further stratified by race to allow over sampling of minorities. Sample size was intended to maximize the efficiency of the sample for comparing different levels of EMTs, as well as for estimating population parameters. Sampling probabilities (i.e., weights) within strata were adjusted to reflect non-response. A two-stage, systematic random selection sampling process was employed based on state use of national EMT registrations as either the sole basis for, or as part of, their initial licensure/relicensure requirements and levels of EMT-Basics and EMT-Paramedics. The precision of the estimates for the sample was calculated to be $+4.2 \%$. Further details of this sampling methodology have been described previously. ${ }^{15-17}$

Individuals were asked to indicate whether they had received training in the areas of WMD, chemical, biological, radiological, decontamination, or pediatric terrorism considerations in their initial EMS provider course, or in any continuing medical education (CME) within the last 24 months. Additionally, providers were asked to indicate whether any training involved "hands-on" components or simulations as a part of the curriculum. Providers also were surveyed as to whether their agencies had equipment designed to respond to these specific emergencies.

Providers were asked to gauge their comfort level in responding to various types of disasters based upon four levels of comfort: (1) very comfortable; (2) comfortable; (3) uncomfortable; and (4) very uncomfortable. In order calculate odds ratios, these choices were dichotomized into two categories. Responses "very comfortable" and "comfortable" were considered comfortable, and responses "uncomfortable" and "very uncomfortable" were considered uncomfortable. Odds ratios are presented with $95 \%$ confidence intervals.

All statistical analyses were conducted using SPSS (SPSS, Inc., Chicago, IL) version 13.0. Basic illustrative tables and figures were created using Microsoft Excel 2002 (Microsoft, Inc., Redmond, WA).

\section{Results}

Of the EMS providers surveyed, 58.9\% had received WMD training within the past 24 months, $57.5 \%$ had received training in decontamination, $54.8 \%$ had received training in biological agents, $52.4 \%$ had received training in chemical agents, $30.8 \%$ had received training in radiological materials, $20.5 \%$ had indicated that terrorism response was a topic covered in their initial provider course, and only $5.4 \%$ of EMS providers surveyed indicated that they had received education in pediatric terrorism considerations (Figure 1).

Attending a general WMD course was associated with comfort in responding to chemical, biological, and radio- 


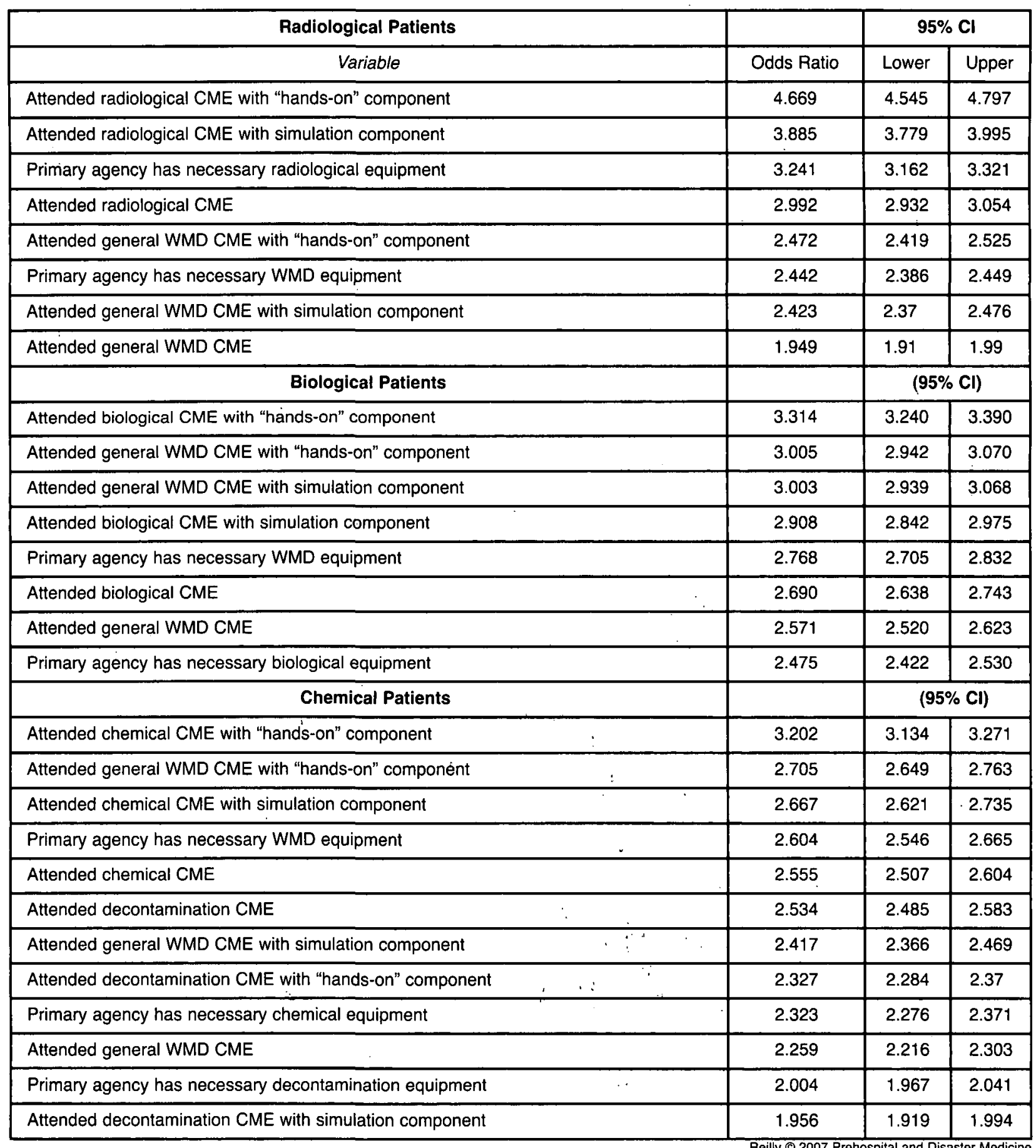

Table 1-Comfort of emergency medical services providers in treating multiple victims of a weapons of mass destruction (WMD) attack based on the type of continuing medical education (CME) training delivered and access to necessary equipment $(\mathrm{CI}=$ confidence interval) 


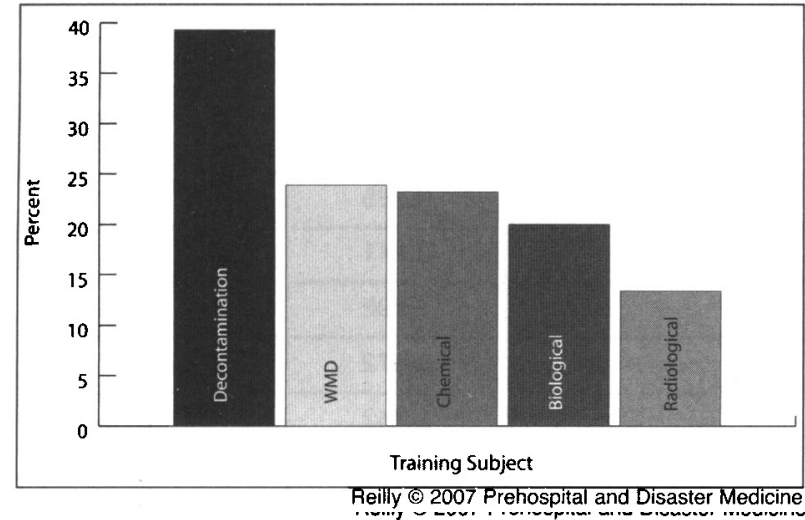

Figure 2-Percentage of continuing education courses within the past 24 months which included a "hands-on" component

logical events. The association was stronger for training that included a simulation component. However, general WMD training that incorporated a "hands-on" component was associated most strongly with comfort in responding to a terrorist event $(\mathrm{OR}=3.0,95 \% \mathrm{CI} 2.9,3.1)$ (Table 1 ).

Only a small percentage of hazard-specific CME courses (chemical, biological, radiological) incorporated a hands-on component (13.4-39.3\%). The percentage of respondents who attended CME programs with a hands-on component is plotted in Figure 2. Providers who indicated there was a hands-on component to their training were more comfortable with the notion of responding to chemical, radiologi$\mathrm{cal}$, and biological disasters, than those who had attended $\mathrm{CME}$ with a simulation component or $\mathrm{CME}$ alone $(\mathrm{OR}=2.47-3.00)$ (Figure 3).

Hands-on training for radiological events was associated more strongly with comfort in responding to radiological emergencies, than hands-on training for any other hazard $(\mathrm{OR}=4.7,95 \% \mathrm{CI}=4.5,4.8)$. When assessing a provider's comfort with performing clinical skills on victims of WMD attacks, hands-on training produced the highest measures of association among all training models, and generally, simulation-based training was more successful than standard CME. (Tables 1 and 2)

Only a small proportion (18.1\%) of providers surveyed indicated that their agencies had the necessary equipment to respond to a WMD event. The types of equipment that were reported by respondents are illustrated in Figure 4. Generally, providers who had equipment were not as comfortable with chemical, biological, or radiological responses as were those who had attended some type of training program (Tables 1 and 3). Additionally, those responders who had received hands-on training were most likely to have the equipment necessary to respond to a terrorist event $(\mathrm{OR}=3.1, \mathrm{CI}=3.0$, 3.2). Providers whose primary EMS agency had the necessary equipment to respond to a WMD hazard or meet the need for decontamination showed a higher comfort level in providing care to victims (Table 3 ).

\section{Discussion}

This analysis supports previous reports that assert that there is a serious lack of adequate training in disaster and terrorism-related emergency response operations for EMS

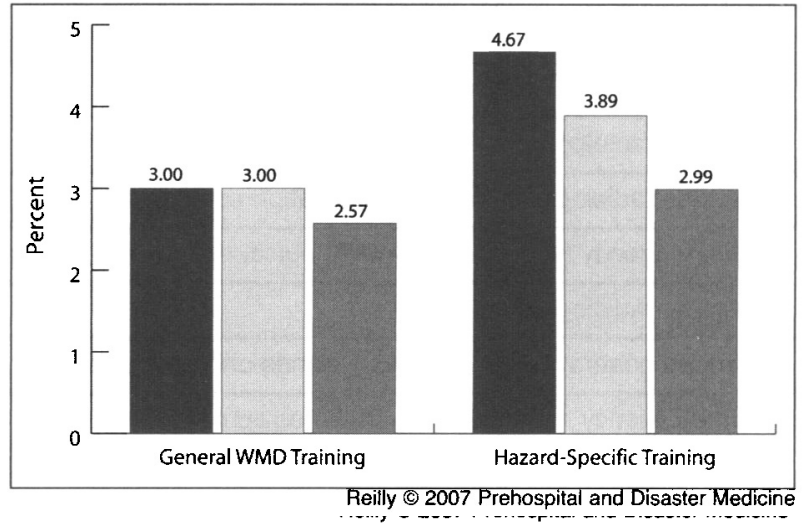

Figure 3-Associated range of comfort-level with type of training received

responders. ${ }^{3,8,13,18-21}$ Responder training that does exist, even at the basic CME level, has been shown to improve the EMS workers' comfort in providing care when responding to disasters. Existing CME programs can be augmented with hands-on or simulation components to increase the retention of critical skills and increase the comfort level of providers when responding to these types of events and rendering care.

Although hands-on training was associated with an increased odds ratio for comfort in hazard-specific trainings, in programs described as general WMD training, providers reported that simulation training produced an almost identical level of comfort as hands-on training. When compared to the significant increase in provider comfort from simulation to hands-on training in a hazard-specific course, this difference may be explained by the "all-hazards" nature of general WMD courses. Providers may need to spend dedicated educational time and energy developing proficiency and comfort with one incident at a time, as opposed to learning about many agents and their necessary responses at once. Further evaluation of the differences in changes in comfort level for general versus incident-specific training is warranted.

An interesting finding was that EMS providers who reported having the necessary equipment to respond to a WMD incident did not always have training in WMD response. Providers who had the necessary equipment to respond to a chemical, biological, or radiological emergency had a lower level of reported comfort in responding to WMD events than their colleagues who had training but no equipment. Equipping prehospital providers to respond to WMD incidents without providing adequate training is akin to providing paramedics with a laryngoscope and not teaching them how to perform intubation. In order for providers to feel comfortable providing patient care and performing skills in the austere environment of a disaster or public health emergency, they must be provided with the necessary education and training.

An additional area of improvement that is needed in EMS disaster training and education is the need for specific training in the clinical and patient care considerations for special and vulnerable populations, including (but not limited to) pediatrics. There is a paucity of information for 


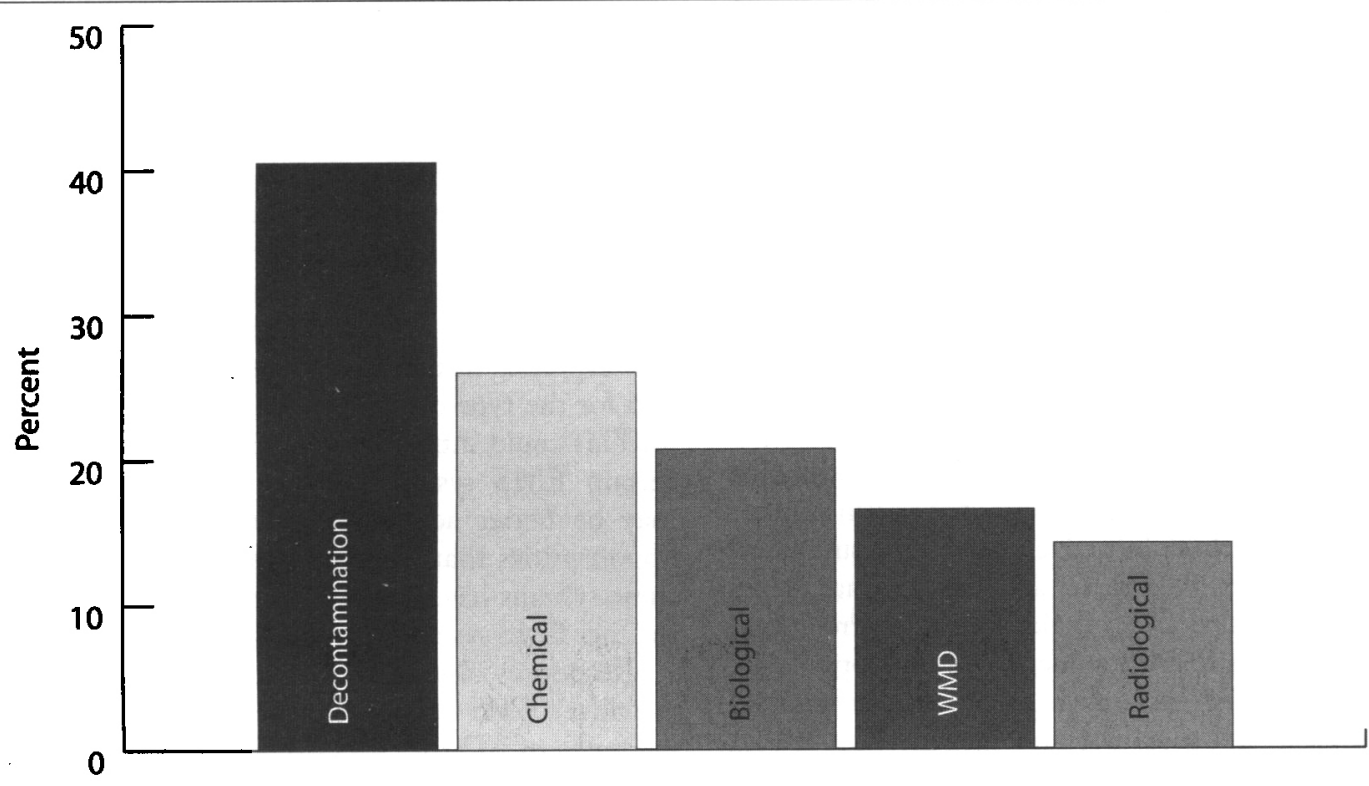

Type of Incident

Reilly @ 2007.Prehospital and Disaster Modicine Figure 4-Percentage indicating that the primary emergency medical services agency had the necessary equipment to respond to the following incidents (WMD = weapons of mass destruction)

\begin{tabular}{|l|c|c|c|c|c|c|}
\hline & \multicolumn{3}{|c|}{ Hands-On } & \multicolumn{3}{c|}{ Simulation } \\
\hline Variable & Odds Ratio & Lower & Upper & Odds Ratio & Lower & Upper \\
\hline Biological & 3.005 & 3.240 & 3.390 & 3.003 & 2.942 & 3.068 \\
\hline Radiological & 2.472 & 2.419 & 2.525 & 2.423 & 2.370 & 2.476 \\
\hline Chemical & 2.705 & 2.649 & 2.763 & 2.417 & 2.366 & 2.469 \\
\hline
\end{tabular}

Table 2-Comparison of comfort-levels in responding to weapons of mass destruction (WMD) events after handson versus simulation assisted training in general WMD courses

\begin{tabular}{|l|c|c|c|}
\hline & Odds Ratio & Lower & Upper \\
\hline Primary agency has necessary radiological equipment & 3.241 & 3.162 & 3.321 \\
\hline Primary agency has necessary biological equipment & 2.475 & 2.422 & 2.530 \\
\hline Primary agency has necessary chemical equipment & 2.323 & 2.276 & 2.371 \\
\hline Primary agency has necessary decontamination equipment & 2.004 & 1.967 & 2.041 \\
\hline
\end{tabular}

Table 3-Comfort of emergency medical services providers in providing care to victims based upon their access to necessary equipment 
educators and trainers in this area. In order to design and implement training and education programs, which will satisfy this deficiency in core provider knowledge, academic centers of excellence, researchers, and professional organizations must work to develop key performance standards and knowledge competencies that can be modeled and used when designing training programs.

With $>80 \%$ of respondents stating that they did not have terrorism or public health emergency response education as a part of their initial provider training, this may be an area for future consideration in EMS educational program development. Initiatives already have been taken by academic and governmental bodies to develop competencies in emergency preparedness and response for health professionals.22,23 Most of these initiatives have been suggested for the public health workforce and for graduate-level health professionals. The DOJ, Office of Justice Programs, and Office for Domestic Preparedness have developed a set of competencies for first responders at the awareness level, performance level, and planning and management levels. These emergency response guidelines contain specific roles and responsibilities for each first responder profession and each level of operational responsibility. ${ }^{24}$ Emergency medical services-specific educational competencies can be created by combining these guidelines with the existing recommendations for the education of health profession students. Until standardized curricula can be modified, EMS educators can use these tools to ensure that prehospital providers are supplemented with the appropriate educational materials to be more effective at responding to these incidents and caring for the victims of these events.

A 2002 report released by HRSA on the national state of trauma system and EMS preparedness for disasters and mass-causality events showed that only one state reported that its EMS system would have access to PPE in the event of a bioterrorism event. ${ }^{3,13}$ Similar research has underscored a general lack of protection for the public health workforce against any type of chemical, biological, or radiological contamination in the event of a disaster. $2,3,8,9,12-14,19,20$

In order for prehospital providers to support and perform decontamination, triage, and provide medical treatment for patients who may be contaminated or infectious, workers must be trained and equipped in the evaluation, selection, and use of PPE for chemical, biological, and radiological hazards. $2,3,5,8,9,12-14,18-20,24$

Additionally, providers must develop an affective and psychomotor mastery of the complexities of delivering patient care in the austere and sensory-limited confinement of PPE. This only will be possible through hands-on training programs and the availability of the necessary equipment. There is a need for targeted funding of EMS systems by national preparedness and equipment grant programs, so that it can be assured that EMS workers will be prepared to provide the necessary level of emergency response that is expected, and is necessary to reduce the morbidity and mortality of disasters.

\section{Limitations}

There were a few potential limitations in this study. Although the sample size was robust at 1,919 persons, the response rate to this survey was only $42.9 \%(823 / 1,919)$ leading to the possibility of non-response bias. In light of this potential limitation, a non-responder survey indicated that there were no differences in socio-demographic factors among respondents. Nevertheless, in future study design, it may be beneficial to use more varied methods of survey response elicitation.

Responses in this survey were not controlled or stratified for the type of EMS system that the provider worked in. This could introduce bias, as one may postulate that in certain EMS systems (fire-based, hospital-based), there may be better access to specific equipment or training opportunities that make it more likely that the workers in these systems have certain equipment or training that those in other EMS systems (private, third-service) would not have.

Responses also were not stratified for the size of the provider's EMS systems. One could propose that due to the existence of MMRS systems, and certain DOD resources that were distributed among the very urban sections of the US, a disparity exists among EMS system preparedness. In fact, this may be a valid assumption. If urban providers were disproportionately represented in the data, this could be a potential source of response bias.

\section{Conclusions}

Lack of training and education, as well as the lack of necessary equipment needed to respond to WMD events, is associated with decreased comfort among emergency medical services providers in responding to chemical, biological, or radiological incidents. Implementing competency-based curriculum enhancements to initial provider education and continuing medical education, along with providing the opportunity for psychomotor skills building, using "handson" training, may increase the confidence and overall comfort levels of prehospital providers to effectively deliver emergency medical care during a disaster or public health emergency. A well-trained and well-prepared EMS system is a critical component of the ability to effectively respond to disasters and public health emergencies.

\section{Acknowledgments}

The authors acknowledge the invaluable assistance provided by the National Registry of Emergency Medical Technicians and its staff without whom this research project could not have been conducted. They also wish to acknowledge the National Registry of EMTs LEADS Project, which provided the mechanism for data collection and provided the data for this project and manuscript. Lastly, they wish to thank the leadership of the National Association of EMTs, who in their ongoing critical efforts to advocate for and support the work done by EMS professionals provided the organizational support for this project. Specifically, they thank Former President Nathan Williams, whose vision allowed the authors to start this project, current President Ken Bouvier, who provided constant guidance and support, and Ms. Lisa Lindsay, whose daily support and assistance was critical to the success of this project. 


\section{References}

1. American College of Surgeons: Resources for Optimal Care of the Injured Patient: 1999. Chicago, IL: American College of Surgeons; 1999.

2. Maniscalco PM, Christen HT: Understanding Terrorism and Managing its Consequences. New Jersey: Brady-Prentice Hall; 2002.

3. United States Department of Health and Human Services: Healtb Resources and Services Administration. Trauma-EMS Systems Program. A 2002 National Assessment of State Trauma System Development, Emergency Medical Services Resources, and Disaster Readiness for Mass Casualty Events. Washington, DC: HRSA, 8/2003.

4. May AK, McGwin G, Lancaster LJ, et al: The April 8, 1998 Tornado: Assessment of the trauma system response and the resulting injuries. $J$ Trauma 1999:47:s25-s33.

5. Roy MJ,(ed): Physician's Guide to Terrorist Attack. Totowa, NJ: Humana Press; 2004.

6. Feliciano DV, Anderson GV, Rozycki GS, et àl: Management of casualties from the bombing at the Centennial Olympics. Am J Surg 1998;176(6):538-543.

7. American College of Surgeons: Disasters from biological and chemical terrorism-What should the individual surgeon do?: A report from the Committee on Trauma. Available at http://www.facs.org/civiliandisasters/trauma.html. Accessed 08 September 2003.

8. Gunaratna R, Chalk P: Jane's Counter Terrorism. 2nd ed. UK: Jane's Information Group, 2002.

9. Barbera JA, Macintyre AG, DeAtley CA: Ambulances to Nowhere: America's Critical Shortfall in Medical Preparedness for Catastrophic Terrorism. In: Howitt AM, Pangi RL (eds.): Countering Terrorism: Dimensions of Preparedness. Cambridge, MA: MIT Press, 2003, pp 283-297.

10. Mann, NC, Mullins RJ, MacKenzie EJ: A systematic review of published evidence regarding trauma system effectiveness. J Trauma 1999; 47;s25-s33.

11. Lillibridge $S:$ New developments in health and medical preparedness related to the threat of terrorism. Prebosp Emerg Care 2003;7:56-58.

12. Baker D: Civilian exposure to toxic agents: Emergency medical response. Prebospital Disast Med 2004;19(2):174-178.

13. Mann NC, MacKenzie E, Anderson C: Public health preparedness for masscasualty events: A 2002 state-by-state assessment. Prebospital Disast Med 2004;19(3):245-255.
14. Klein KR, Atas JG, Collins J: Testing emergency medical personnel response to patients with suspected infectious disease. Prebospital Disast Med 2004;19(3):256-265.

15. Brown WE Jr, Dawson D, Levine R: Compensation, benefits, and satisfaction: The Longitudinal Emergency Medical Technician Demographic Study (LEADS) Project. Prebosp Emerg Care 2003;7(3):357-362.

16. Brown WE Jr, Dickison PD, Misselbeck WJ, Levine R: Longitudinal Emergency Medical Technician Attribute and Demographic Study (LEADS): An interim report. Prebosp Emerg Care 2002;6(4):433-439

17. Dawson DE, Brown WE Jr, Harwell TS: Assessment of nationally registered emergency medical technician certification training in the United States: The LEADS Project. Longitudinal Emergency Medical Technician Attributes Demographic Study. Prebosp Emerg Care 2003;7(1):114-119

18. United States General Accounting Office: Report to Congressional Committees. Hospital Preparedness: Most Urban Hospitals Have Emergency Plans but Lack Certain Capacities for Bioterrorism Response. GAO-03-924. Washington, DC: GAO, 8/2003.

19. Ghilarducci DP, Pirallo RG, Hegmann KT: Hazardous materials readiness of the United States Level-I Trauma Centers. Occup Environ Med 2000; 42(7):683-692.

20. Rubin JN: Recurring pitfalls in hospital preparedness and response. Available at http:/www.homelanddefense.org/journal/Articles/rubin.html. Accessed 24 March 2004.

21. United States Congress Senate Committee on Governmental Affairs: Combating Terrorism: Considerations for Investing Resources in Chemical and Biological Preparedness. Statement of Henry L. Hinton, Jr., Managing Director, Defense Capabilities and Management. General Accounting Office. GAO-02-162T. Washington, DC: GAO, 10/17/2001.

22. Columbia University School of Nursing Center for Heaith Policy: Bioterrorism and Emergency. Readiness: Competencies for all Public Health Workers. Columbia: School of Nursing, Center for Health Policy, 2002.

23. Association of American Medical Colleges: AAMC issues new report on bioterrorism education for medical students. Newsroom-Press release. Available at http://www.aamc.org/newsroom/pressrel/2003/030707.htm. Accessed 14 July 2003.

24. United States Department of Justice, Office of Justice Programs, Office for Domestic Preparedness: Emergency Responder Guidelines-First Responder Guidelines. Washington, DC: USDOJ, 8/1/2002. 